Sharif University of Technology
Scientia Iranica
SCIENTIA
I RAN I C A
http://scientiairanica.sharif.edu

\title{
Collapse assessment of protected steel moment frame under post-earthquake fire
}

\author{
P. Mirzaei and M. Gerami* \\ Department of Civil Engineering, Semnan University, Semnan, P.O. Box 3513119111, Iran.
}

Received 7 July 2018; received in revised form 27 November 2018; accepted 19 January 2019

\section{KEYWORDS}

Fire after earthquake; Fireproofing;

Heat transfer;

Side-way collapse;

Thermal-mechanical analysis.

\begin{abstract}
This paper investigates the behavior of low-, medium-, and high-rise protected steel moment-resisting frames under post-earthquake fire through two different methods. In the first method, the pushover analysis was utilized to simulate the response of the sample structures for various target displacements. Then, the thermal-mechanical analysis was implemented to evaluate the behavior of the damaged frames under fire, assuming that the fireproofing was delaminated at the end regions of the beams. In the second method, the seismic response of the frames under two sets of the MCE-scaled near- and far-fault ground motion records was determined employing the time history analysis. In this method, the damage of fireproofing was characterized by the maximum inter-story drift ratio. The results of the study revealed that the first method produced similar results to that of the second method for most cases. It was also found that for sufficiently large drift demands, the collapse of the frames under post-earthquake fire occurred in the side-way mode, while for lower seismic responses, the local failure of beams dominated other failure modes. Moreover, it was found that the reduction of fire resistance time due to the effects of Maximum Considered Earthquake (MCE) seismic loads ranged from $4 \%$ to $27 \%$ for the considered structures.

(C) 2020 Sharif University of Technology. All rights reserved.
\end{abstract}

\section{Introduction}

There have been a large number of disastrous fire events caused by seismic excitations that have led to massive human and financial losses [1]. In some of the major earthquakes around the world, the amount of loss due to the post-earthquake fire was more severe than or comparable with those produced by ground excitations (e.g., Tokyo (1923), Loma Prieta (1989), Northridge (1994), Kobe (1995)) [2]. The considerable destructive outcomes of post-earthquake fire urged the structural engineers to conduct experimental and analytical re-

*. Corresponding author. Fax: +982333321005 E-mail addresses: p_mirzaei@semnan.ac.ir (P. Mirzaei); mgerami@semnan.ac.ir (M. Gerami)

doi: 10.24200 /sci. 2019.51391 .2148 searches on the behavior of various types of structural systems under post-earthquake fire loads [3]. The risk attenuation surveys imply that an increase in fire resistance time by strengthening the structural components reduces the risk level against post-earthquake fire both on local and urban scales [4]. Severe earthquakes may impose significant deformation on the structural systems, which can cause delamination of fireproofing in different parts of the structural elements. Also, the residual drifts (geometric damage) can be considerably large, especially for ductile structures such as steel moment-resisting frames. Superposition of geometric damage and delamination of fireproofing in the structural elements increase the vulnerability of structures against fire loads. In addition, the post-earthquake fire is more intense than regular fire events. The shortage of water supply reservoirs, drop of water pressure, traffic jam and obstruction of transportation routes, 
insufficient number of firefighters to serve all of the fire happenings, probable damages to fire extinguishment equipment, and some other factors altogether lead to increase in fire intensity after severe earthquake events. This requires a more conservative design in the fire condition to provide more resistance time than regular fire events.

The effect of geometric damage on the resistance time of structures under fire loading has been investigated by some researchers. Della Corte et al. studied the behavior of steel moment-resisting frame structures under post-earthquake fire using numerical models and concluded that residual deformations and P-delta effect would reduce resistance time against fire [5]. Faggiano investigated the behavior of deformed portal frames under fire loads [6]. The results of that study revealed that the reduction of fire resistance time due to the residual drifts would not be considerable if the drift demands due to seismic loads did not exceed the Life Safety (LS) performance level. In another research, Faggiano et al. defined the performance levels for fire loading conditions [7]. Accordingly, the performance levels were determined based on the size of the damage produced by fire loads, extending from operating in fire to collapse prevention in fire. Zaharia and Pintea investigated the effect of residual drifts and the change in fire loading curve for post-earthquake cases compared to the regular fire events [8]. It was found that the size of damage to the structural members due to the seismic loads and the fire intensification considerably affected the fire resistance of the structures. Behnam and Ronagh investigated different fire scenarios for high-rise steel frame structures [9]. The investigation of different fire scenarios including constant fire and vertically traveling scenarios revealed that the fire scenario affected both the fire resistance time and failure mode of the structures under postearthquake fire. In another research, Behnam and Ronagh analyzed the behavior of two sample structures with the same geometric configuration: one designed as a residential building and the other designed as a school structure [10]. They found that the design specifications dominate the behavior of the frames under fire loads, as the school structure endured a longer time under pre- and post-earthquake fire loads. Memari et al. studied the behavior of the steel moment frames with Reduced Beam Section (RBS) connection in fire after earthquake, considering the seismic damage to the fireproofing components at the reduced section zones [11]. They found that with the increase of the Inter-story Drift Ratio (IDR), the fire resistance of the structures decreased in all of the considered fire scenarios. Elhami Khorasani et al. scrutinized the performance of a 9-story steel frame under postearthquake fire considering uncertainty in material characteristics and fire loading parameters [12]. The results of their study revealed that the upper stories were more susceptible to fire loads since the beam section at the upper stories was commonly smaller than that on the middle or bottom stories. Behnam studied the performance of regular and irregular frames against fire loads and deduced the poorer behavior of irregular frames under fire loads than regular frames [13]. Their study investigated vertical irregularity and the global failure mechanism.

To the best of the author's knowledge, in most of the researches conducted on the behavior of structural systems under post-earthquake fire, the effect of damage to the fireproofing is either ignored or considered approximately. For example, in some of the studies, it has been assumed that the entire fireproofing at two ends of the beams is completely removed in case of seismic loads. This assumption is conservative, but not realistic. It has been proved that the damage of fireproofing depends on the deformation demands and properties of the fireproofing. For example, Braxtan and Pessiki conducted an experimental study of the large-scale beam-column assemblies to examine the bond of the Spray-applied Fire Resistive Material (SFRM) to steel in the beam-column connection region [14]. They found that the damage of the SFRM at the vicinity of the beam-column connections began with debonding of the SFRM from the steel when the IDR demand reached about $1.0 \%$. However, even though the SFRM was debonded from the yielded portions of the connection at this drift level, the three-dimensional geometry of the SFRM in the beamcolumn connection prevented the SFRM from falling off the connection region. When the IDR demand reached about $3 \%$, inelastic buckling in the beam flanges caused the SFRM to fall away from the connection and to expose the steel at those locations. In another work, Leo Braxtan and Pessiki developed an experimental study on the bond performance of the SFRM in steel plates subjected to tensile yielding [15]. The test results showed rapid degradation of the bond strength of SFRM to steel plates with increasing tensile yielding. Keller and Pessiki investigated the effect of earthquakeinduced SFRM spalling on the side-way response of steel moment frames under fire using the numerical modeling approach [16]. The results of their study revealed that elimination of fireproofing components led to a considerable reduction in rotational stiffness and bending moment resistance of the connection. This reduction in rotational stiffness would increase the flexibility of the structural system for side-way motion and exacerbate drift demands under the action of residual destabilizing forces $(P-\Delta)$ under postearthquake fire.

The focus of this study is to accurately investigate the effect of damage of the fireproofing on the resistance time and collapse mechanism of steel moment-resisting 
frames under post-earthquake fire. To this end, the results of seismic and thermal-mechanical analyses are combined to accurately consider the behavior of seismically loaded structures under fire loads. The fire resistance time of three sample steel moment frames for pre- and post-earthquake situations is compared to specify the reduction of fire resistance time due to the seismic effects. Considering the fact that nearfault excitations may induce more significant effects than far fault motions, the investigations are distinctly performed on two sets of near and far fault ground motion records, each with seven accelerograms. The results of this study offer a realistic insight into the effects of seismic loads on the fire resistance of the protected steel moment-resisting frame structures.

\section{Methodology}

To investigate the effect of seismic loads on the behavior of the structures under fire, the fire resistance time for 3 sample frames with 5,10 , and 15 stories was compared in pre- and post-earthquake conditions. The geometric configuration of the sample frames complied with the short- to high-rise building specifications. In the post-earthquake condition, the thermal-mechanical analysis began after seismic analysis. Two different methods were employed to investigate the behavior of the sample structures under post-earthquake fire. In the first method, the pushover analysis with different target roof displacements was carried out to find the response of the sample frames to seismic loads with different intensities. Then, the thermal-mechanical analysis of the damaged structure was performed, assuming that fireproofing was delaminated at the end regions of the beam member (due to the seismic effects). Despite sum approximation, this approach provides data so that the geometric damage relates to the behavior of the structure under fire.

In the second method, the nonlinear time-history analysis was employed to precisely determine the response of structures to seismic excitations. Two sets of near- and far-fault ground motion records with seven accelerograms were scaled to Maximum Considered Earthquake (MCE) intensity and employed for performing time history analysis. In the thermalmechanical analysis phase, it was assumed that fireproofing at the end regions of the beams was removed on those stories where the IDR demand during seismic loading exceeded $2.5 \%$. The results of post-earthquake analyses were interpreted based on the resistance time and the detected failure mode.

\subsection{Sample structures}

The sample structures included three special steel moment frames with 3 bays of $5 \mathrm{~m}$ width. The height of the stories is $3.5 \mathrm{~m}$ for all cases. Height to width ratio of 5-, 10-, and 15-story frames complies with the common criteria for short-, medium-, and high-rise structures, respectively. The considered frames are the middle frame of $3 \mathrm{D}$ symmetric steel structures with a one-way slab system. Considering that middle frames carry a greater portion of gravity loads, they are more vulnerable to fire loads [17].

Gravity loading of the frames is based on the Iranian national building code no. 6 [18]. Accordingly, $20 \%$ of nominal live load is considered in gravity loading for fire analysis and calculation of seismic masses. Therefore, the beam members carry distributed loads of $1600 \mathrm{~kg} / \mathrm{m}$. Moreover, concentrated loads of $8000 \mathrm{~kg}$ and $4000 \mathrm{~kg}$ are applied to the middle and corner columns due to transmitted loads from the beams of perpendicular frames.

Design of the sample frames was performed in compliance with the specifications of Iranian seismic design code (Standard no. 2800) [19] for high-seismicity regions. Accordingly, the base acceleration is considered $0.35 \mathrm{~g}$ and the soil of type II is considered for the site condition. The structural design of the frames is based on the ANSI/AISC 360-10 specifications [20]. The St-37 steel with a yield stress of $240 \mathrm{MPa}$ and elastic modulus of $210 \mathrm{GPa}$ is used for the structural members. The cross-section of beams and columns is made compact to avoid the local failure and provide maximum ductility. Lateral bracings of the beams are so close that prevent lateral and torsion buckling during severe seismic loads. The geometric dimensions and configuration of sample frames as well as the plan of the main structures are depicted in Figure 1. Meanwhile, the design sections are presented in Table 1.

\subsection{Numerical modeling}

Nonlinear modeling of the sample structures was performed by using finite element ABAQUS software. This program verifiably yielded accurate results of seismic analysis of the frame structures [21]. Moreover, the accuracy of the modeling technique used for thermalmechanical analysis is validated in Section 2.3.

The finite element models are prepared in the twodimensional space. At the first step, a heat transfer analysis is performed to determine the variation in the temperature of different points of the structures during fire loading. Given the time-temperature curves at different points of the frames, thermal-mechanical analysis would begin immediately after application of gravity loads (for undamaged state) or after seismic analysis (for damaged state). The results of fire analysis are interpreted based on the stress, strain, and deformations. For modeling the heat transfer process, the column and beam members are modeled using D1 frame element involving a heat transferring link element (DC1D2). In mechanical models, the beams and columns are modeled by two-nodded B21 
Table 1. Design sections of the sample structures.

\begin{tabular}{ccccc}
\hline Sample frame & Story & Corner columns & Middle columns & Beams \\
\hline & $1-3$ & HEB 600 & HEB 800 & IPE 450 \\
& $4-7$ & HEB 400 & HEB 600 & IPE 450 \\
15-story frame & $8-12$ & HEB 340 & HEB 600 & IPE 450 \\
& $13-14$ & HEB 240 & HEB 340 & IPE 330 \\
& 15 & HEB 240 & HEB 340 & IPE 300 \\
& $1-5$ & HEB 340 & HEB 450 & IPE 360 \\
10-story frame & 6 & HEB 260 & HEB 340 & IPE 360 \\
& $7-9$ & HEB 260 & HEB 340 & IPE 300 \\
& 10 & HEB 260 & HEB 340 & IPE 270 \\
& $1-3$ & HEB 240 & HEB 300 & IPE 300 \\
5 -story frame & 4 & HEB 240 & HEB 280 & IPE 270 \\
& 5 & HEB 240 & HEB 280 & IPE 240 \\
\hline
\end{tabular}

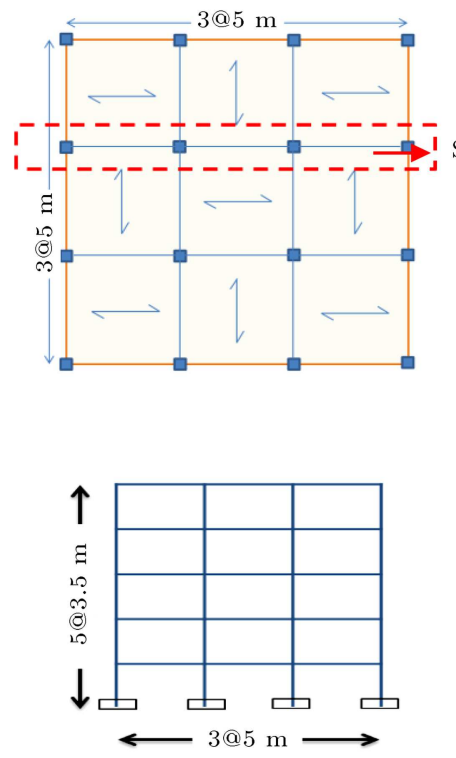

Selected frame
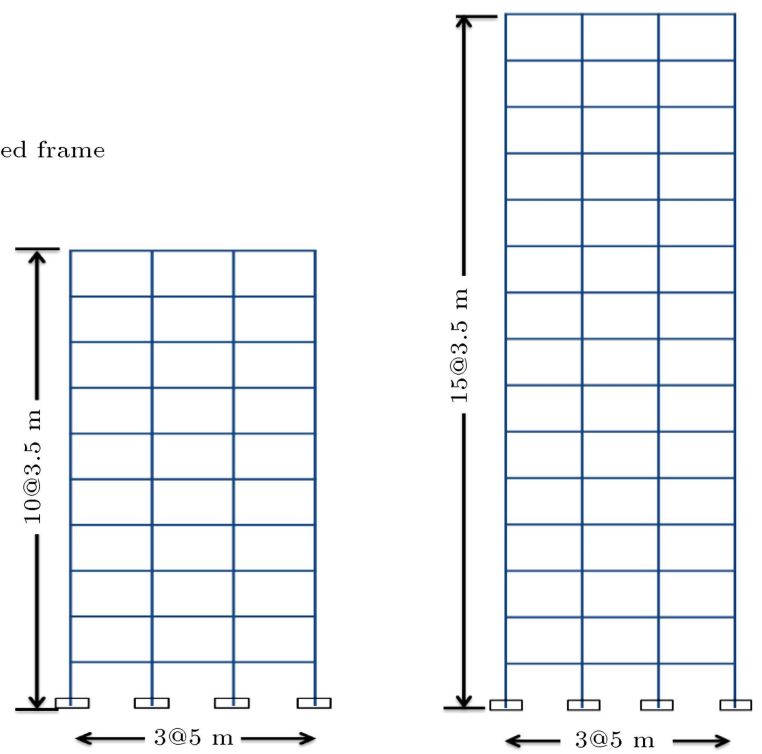

Figure 1. Configuration of the sample structures.

beam elements. Mechanical behavior of the structures under fire loading is analyzed based on Rankin's theorem [22].

Panel zone of beam-to-column connections is modeled by the scissor model proposed by Charney and Marshall [23]. This model comprises two rigid links pinned to each other at the middle length while a rotational spring connects them together. The stiffness of the spring is determined based on the dimensions of beam and column sections using the expressions provided in Figure 2.

Mechanical behavior of the steel material at different temperatures is specified by the expression given in Eurocode 3 standard [24]. A bilinear elastic-perfectly plastic curve defines the cyclic behavior of the steel material, as shown in Figure 3.

Variation of the thermal characteristics of steel material in terms of temperature is considered in accordance with Eurocode 3 specifications. The variation of longitudinal expansion coefficient, thermal conductivity, and specific heat of the mild steel at different temperatures are given in Figure 4.

In structural modeling, rigid diaphragm is assigned to the floor levels. Also, the damping ratio of $5 \%$ is assumed for time-history analyses. The effect of concrete slab on the thermal-mechanical behavior of the frames under fire loads is negligible since the fast thermal expansion rate of the steel girders produces 

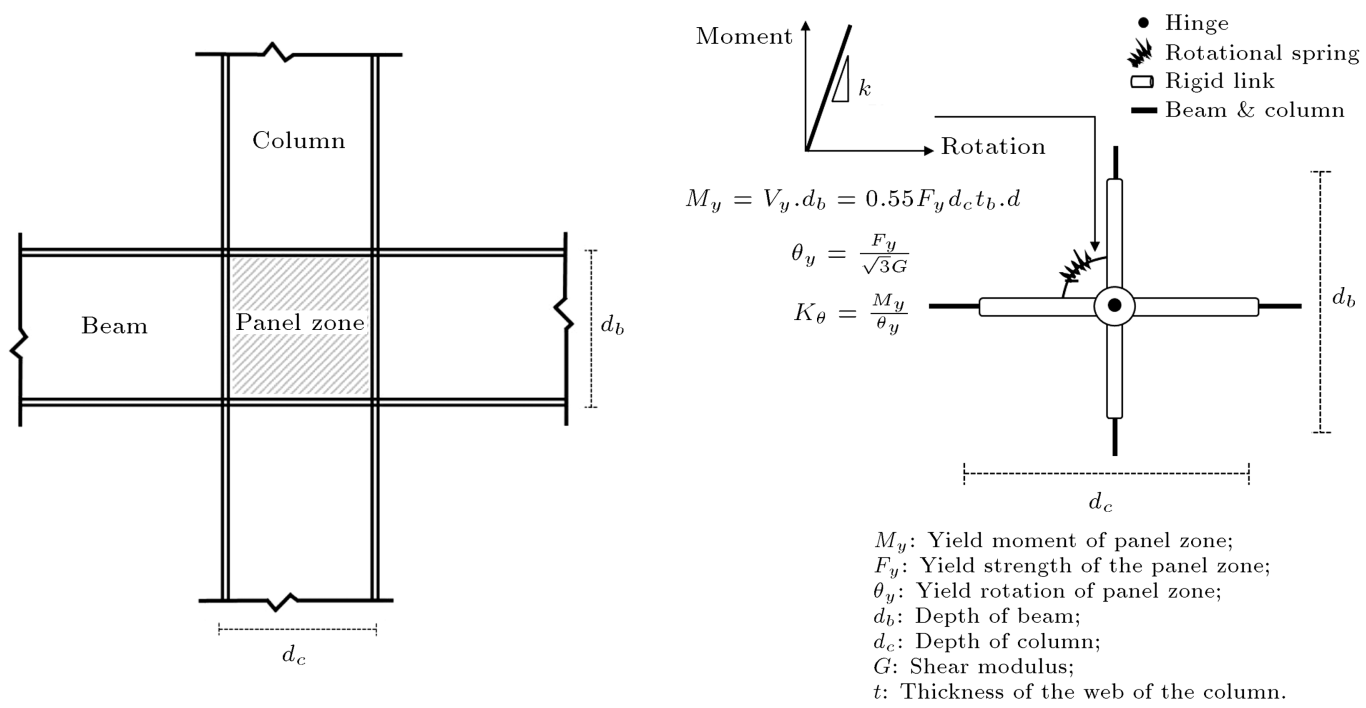

Figure 2. Components of scissor panel zone model.

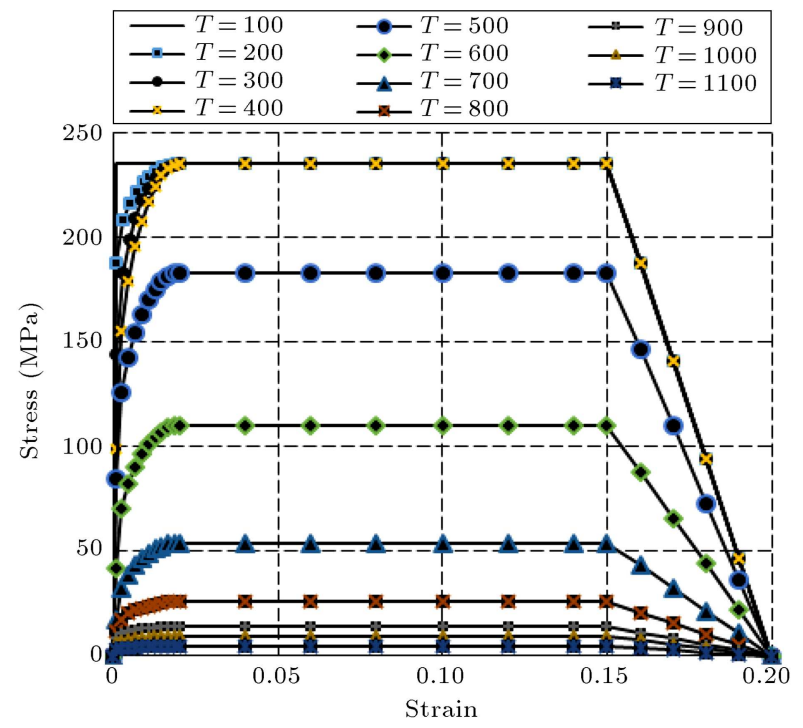

Figure 3. Elastic-perfectly-plastic behavior of steel material at elevated temperatures.

considerable tensile loads on the concrete slab, causing deformation of cracks within the slab. Therefore, minimum stresses remain on the concrete slabs and incorporation of their structural effects can be neglected in the $2 \mathrm{D}$ stress analysis of frames [17,25]. However, the effect of the presence of the concrete floor slabs is indirectly taken into consideration in the transient heat transfer analysis. Accordingly, it is assumed that the beam members are exposed to fire at three faces (one face is protected by the slab system).

\subsection{Modeling validation}

A generic 2D steel frame is selected for validation of the modeling technique used for thermal-mechanical analyses. This model was firstly experimented by Rubert and Schaumann to investigate standard fire loading effects on moment-resisting frame structures [26]. This model has been analyzed by some other researchers [27$29]$.

The geometric configuration and loading details of this frame are shown in Figure 5. The IPE 80 is used for all beams and columns. The members located at the left part of the frame are heated according to the implications of ISO 834 standard fire.

Fire analysis is performed using ABAQUS software. The variation of horizontal displacement for two nodes of the frame in terms of temperature variation is obtained from fire analysis, the results of which are
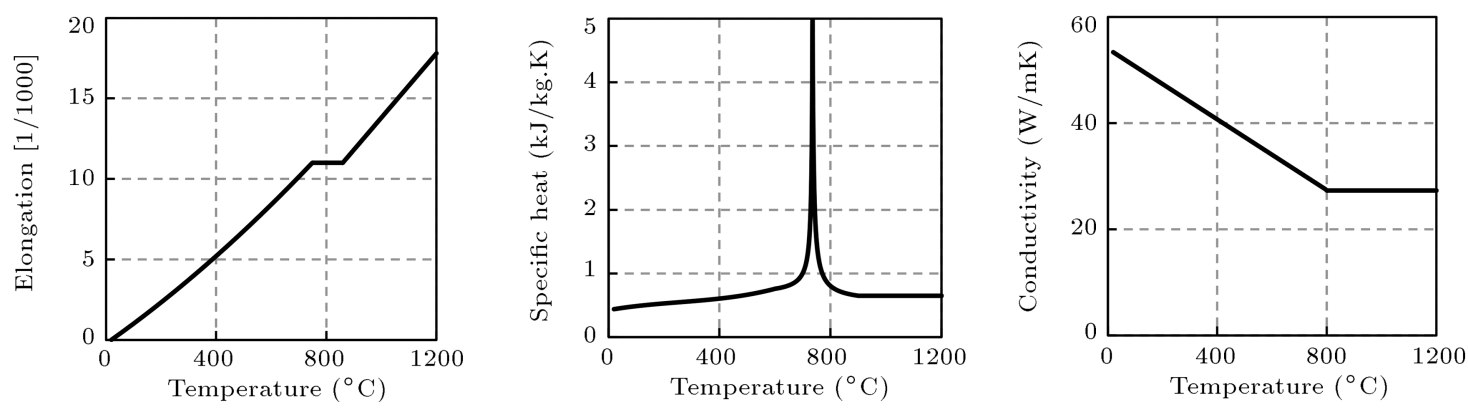

Figure 4. Variation of steel thermal characteristics in terms of temperature. 


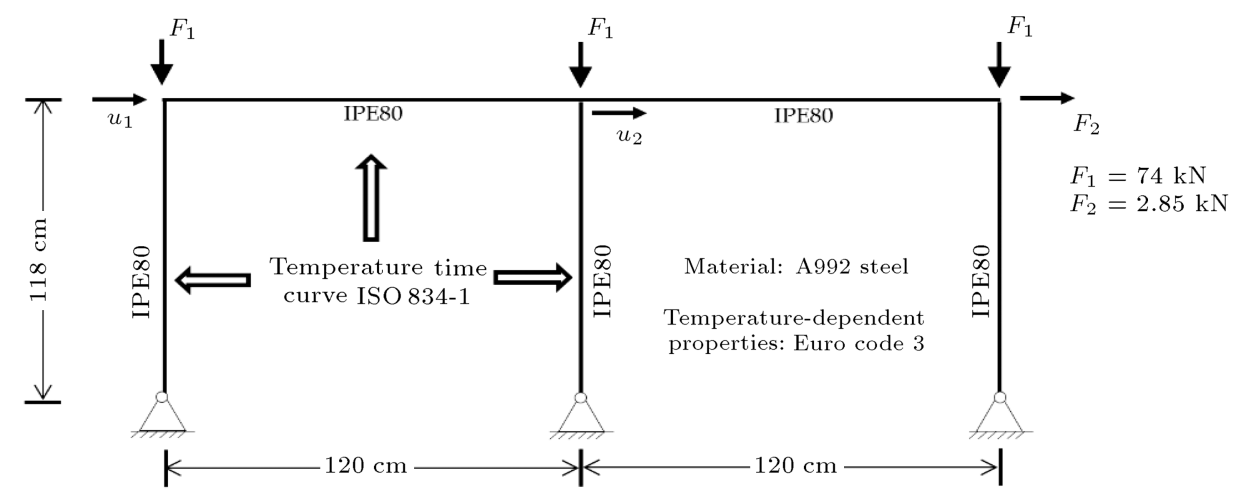

Figure 5. Details of verification model.
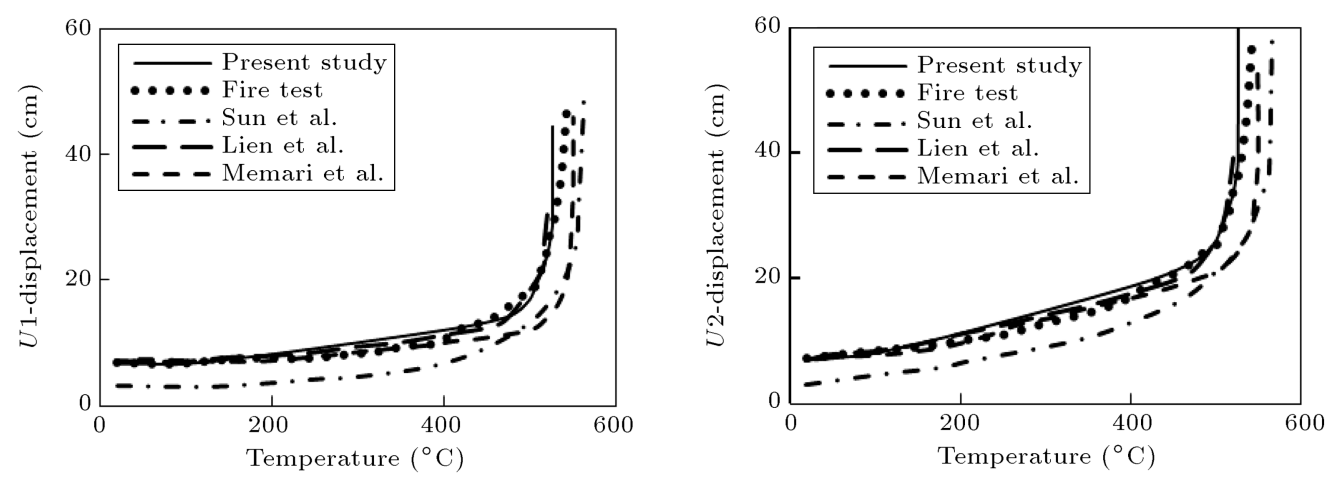

Figure 6. Comparison of validation analysis results and those of other researches.

compared with those obtained from previous experimental and numerical analyses, as given in Figure 6 . The results of the analysis conducted by the considered modeling technique are in good agreement with those of the previous researches and experiments, given that the maximum error is below $3 \%$.

\subsection{Ground motion records}

Two ensembles of near-fault and far-fault ground motion records are used for the time history analysis. Each of the ground motion sets includes seven records scaled to the MCE hazard level. The far fault records are recorded at far distances to fault and impulsive characteristics are excluded. In contrast, the near-fault records are recorded at near distances to fault and at least, one strong pulse is incorporated in their velocity time history. The near-fault records satisfy the criteria proposed by Baker for identification of pulse-like nearfault records [30]. On this basis, the near-fault records satisfy the following requirements:

1. The velocity pulse appears at the beginning of the record;

2. The Peak Ground Velocity (PGV) of the recorded accelerogram is greater than $30 \mathrm{~cm} / \mathrm{s}$;

3. The Pulse Indicator (PI) is greater than 0.85 . PI is a parameter that measures the ratio of pulse energy to the total energy released by the ground motion record.

The major characteristics of near-fault records are provided in Table 2. The fault normal component of

Table 2. Near-fault ground motion records.

\begin{tabular}{clccccc}
\hline No. & \multicolumn{1}{c}{ Earthquakes, Years } & $\boldsymbol{M}_{\boldsymbol{W}}$ & $\boldsymbol{R}(\mathbf{k m})$ & $\boldsymbol{T}_{\boldsymbol{p}}(\mathbf{s})$ & $\mathbf{P G V}(\mathbf{c m} / \mathbf{s})$ & RVA $(\mathbf{s})$ \\
\hline 1 & Nigata Japan, NIGH 11, 2004 & 6.6 & 8.9 & 1.8 & 36.4 & 0.08 \\
2 & Kobe, Japan, Takatori, 1995 & 6.9 & 1.47 & 1.6 & 170 & 0.25 \\
3 & Chi-Chi, Taiwan, TCU076, 1999 & 7.6 & 2.76 & 4 & 64 & 0.23 \\
4 & Northridge-01, Jensen Filter Plant, 1994 & 6.7 & 5.43 & 3.5 & 67 & 0.13 \\
5 & Superstition Hills-02, Parachute Test Site, 1987 & 6.5 & 0.95 & 2.3 & 107 & 0.26 \\
6 & Morgan Hill, Coyote Lake Dam (SW Abut), 1984 & 6.2 & 0.53 & 1 & 62 & 0.08 \\
7 & Imperial Valley-06, EC Meloland Overpass FF, 1979 & 6.5 & 0.07 & 3.3 & 115 & 0.31 \\
\hline
\end{tabular}


Table 3. Far-fault ground motion records.

\begin{tabular}{clccccc}
\hline No. & \multicolumn{1}{c}{ Earthquakes, Years } & $\boldsymbol{M}_{\boldsymbol{W}}$ & $\boldsymbol{R}(\mathbf{k m})$ & $\boldsymbol{T}_{\boldsymbol{m}}(\mathbf{s})$ & $\mathbf{P G V}(\mathbf{c m} / \mathbf{s})$ & $\mathbf{R V A}(\mathbf{s})$ \\
\hline 1 & Chi-Chi CHY101-W, Taiwan, September 20, 1999 & 7.6 & 11.14 & 1.29 & 70.64 & 0.2 \\
2 & Imperial Valley, H-E01240, October 15, 1979 & 6.5 & 10.4 & 0.75 & 31.58 & 0.1 \\
3 & Loma Prieta, G03090, October 18, 1989 & 6.9 & 14.4 & 0.92 & 39.03 & 0.12 \\
4 & Northridge, CNP 196, January 17, 1994 & 6.7 & 15.8 & 0.8 & 60.7 & 0.15 \\
5 & Tabas, BOS-T1, September 16, 1978 & 7.4 & 26.1 & 0.77 & 15.44 & 0.11 \\
6 & Kobe, HIK000, January 16, 1995 & 6.9 & 95.72 & 0.9 & 20.22 & 0.23 \\
7 & N. Palm Springs, TFS000, July 8, 1986 & 6.06 & 64.8 & 0.37 & 6.9 & 0.06 \\
\hline
\end{tabular}
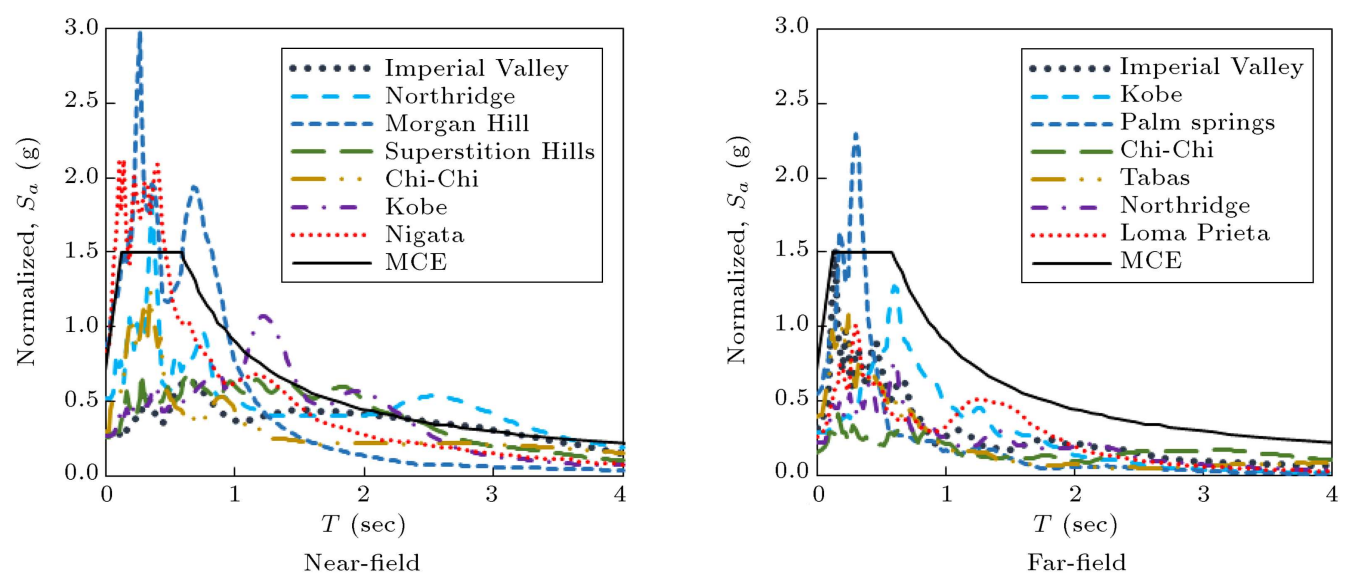

Figure 7. Response spectrum of the normalized records.

the near-fault records is employed for running the time history analyses. The far fault records are introduced in Table 3.

The scaling of the records is accomplished based on the methodology proposed in FEMA P695 standard [31]. Accordingly, the ground motion records are firstly normalized based on the PGV values and scaled in a manner that the median of the acceleration response of the records in the first mode period corresponds to the target spectrum. Thus, the scale factor of the records is a function of the response spectrum of the record and the fundamental period of vibration for the structures under study. Thus, the near and far fault records are separately scaled to reach the hazard level of $2 \%$ probability of exceeding 50 years. The acceleration response spectrum of the selected records accompanying the target spectrum is presented in Figure 7 . The target spectrum is related to the ordinary office construction located at a site near the Los Angeles city with the seismic design category D.

\subsection{Fire scenarios}

A single compartment fire scenario is considered for performing thermal-mechanical analysis on the sample structures. Accordingly, it is supposed that fire spreads all spans of the stories located at the bottom $3 / 5$ th height of the structures. For example, the 1st to 6th stories of the 10-story frame are exposed to fire. The frame members of the sample structures are firstly protected by the SFRM fireproofing. However, in cases where the seismic loads produce IDR demands of greater than $2.5 \%$ in any of the stories, the SFRM is delaminated at two ends of the beam members belonging to that story. Following the results of previous experimental researches [14], the length of the beam at two ends expected to lose fireproofing is considered as the depth of the beam cross-section. Using this approach, the damage of the SFRM due to the seismic loads is taken into account.

\section{Heat transfer analysis under standard fire}

Thermal-mechanical analysis is composed of two consecutive steps. In the first phase, the variation in ambient temperature versus time is determined. In the next phase, the variation in body temperature of structural components is specified considering the section shape of members and thickness and thermal characteristics of the fireproofing components. Heat transfers to the structural members through different mechanisms including conduction, convection and radiation, which must be taken into account for calculating the body temperature of different structural members. 
The compartment time-temperature function employed for this research is based on the provisions of ISO834 standard, which is adopted by European standard of EN1991-1-2 [32]. This expression is provided in Eq. (1).

$$
\theta_{c r}=20+345 \log _{10}(8 t+1)
$$

where $t$ is the time elapsed after the beginning of fire in terms of minutes. The time-temperature curve of the beams is separately calculated in protected and unprotected states. In the unprotected state, it is assumed that fireproofing is damaged in some parts of the beam, leading to direct exposure of the member to fire.

Fireproofing of the protected members is made of spray vermiculite-cement SFRM with mass density of $300 \mathrm{~kg} / \mathrm{m}^{3}$, thermal conductivity of $0.12 \mathrm{~W} / \mathrm{mK}$, and specific heat of $1200 \mathrm{~J} / \mathrm{kgK}$. SFRM thickness for providing a minimum of 2-hour resistance under standard fire is calculated by the experimental approach according to the methodology proposed by UL 263 Standard [33]. The thickness of SFRM coatings for the beams and columns is given in Table 4 .

The variation in temperature for the beams and columns is obtained using Ozone software [34]. Considering that the protected or unprotected beams with different cross-sections experience approximately the same rate of temperature change, an identical timetemperature curve is considered for the protected and

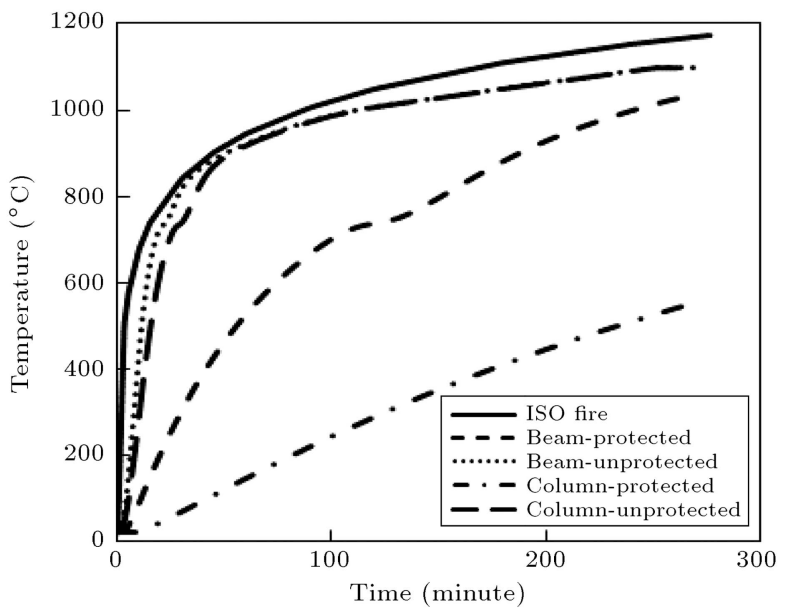

Figure 8. Time-temperature curve of the frame members under standard fire.

unprotected beams. The columns are treated in the same manner. The time-temperature curves of the beams and columns under the standard fire associated with the protected and unprotected states are provided in Figure 8.

\section{Thermal-mechanical analysis}

The collapse of the structural systems under fire loads mainly occurs in 3 different modes:

Table 4. Spray-applied Fire Resistive Material (SFRM) thickness for structural members.

\begin{tabular}{llccccccc}
\hline Section & Type & Height & $\begin{array}{c}\text { Thick } \\
\text { of web }\end{array}$ & $\begin{array}{c}\text { Width of } \\
\text { flange }\end{array}$ & $\begin{array}{c}\text { Thick of } \\
\text { flange }\end{array}$ & $\begin{array}{c}\boldsymbol{H}_{\boldsymbol{p}} / \boldsymbol{A} \\
\boldsymbol{W} / \boldsymbol{D}\end{array}$ & $\begin{array}{c}\text { Fireproof thick } \\
(\mathbf{m m})\end{array}$ \\
\hline HEB 240 & Column & 240 & 10 & 240 & 17 & 139 & 0.96 & 59.59 \\
HEB 260 & Column & 260 & 10 & 260 & 17.5 & 136 & 0.99 & 58.19 \\
HEB 280 & Column & 280 & 10.5 & 280 & 18 & 131 & 1.02 & 56.28 \\
HEB 300 & Column & 300 & 11 & 300 & 19 & 124 & 1.08 & 53.39 \\
HEB 340 & Column & 340 & 12 & 300 & 21.5 & 113 & 1.19 & 48.35 \\
HEB 400 & Column & 400 & 13.5 & 300 & 24 & 103 & 1.30 & 44.18 \\
HEB 450 & Column & 450 & 14 & 300 & 26 & 98 & 1.37 & 41.97 \\
HEB 600 & Column & 600 & 15.5 & 300 & 30 & 90 & 1.49 & 38.53 \\
HEB 800 & Column & 800 & 17.5 & 300 & 33 & 85 & 1.58 & 36.33 \\
IPE 240 & Beam & 240 & 6.2 & 120 & 9.8 & 223 & 0.60 & 16.87 \\
IPE 270 & Beam & 270 & 6.6 & 135 & 10.2 & 212 & 0.63 & 16.44 \\
IPE 300 & Beam & 300 & 7.1 & 150 & 10.7 & 200 & 0.67 & 15.95 \\
IPE 330 & Beam & 330 & 7.5 & 160 & 11.5 & 188 & 0.71 & 15.45 \\
IPE 360 & Beam & 360 & 8 & 170 & 12.7 & 174 & 0.77 & 14.78 \\
IPE 400 & Beam & 400 & 8.6 & 180 & 13.5 & 164 & 0.82 & 14.31 \\
IPE 450 & Beam & 450 & 9.4 & 190 & 14.6 & 153 & 0.88 & 13.72 \\
\hline
\end{tabular}



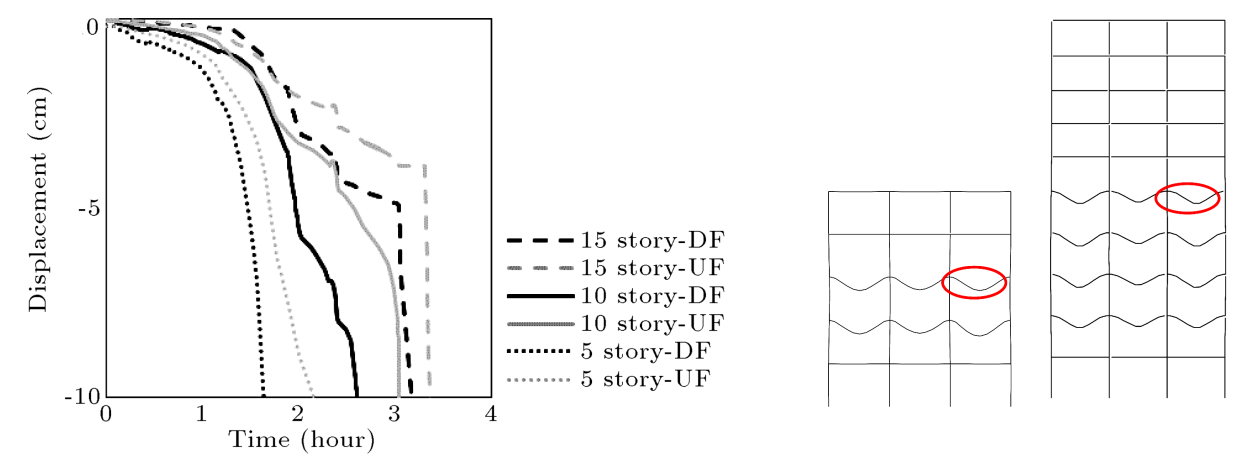

Figure 9. Deflection curve of a sample beam for undamaged structures under standard fire.

(i) Yield of beam members;

(ii) Buckling of columns;

(iii) Side-way collapse.

The occurrence of the mentioned collapse mechanisms depends on the factors such as structural characteristics, fireproofing, and geometric damage. The resistance time of the frames is the time at which any of the above-mentioned collapse modes is detected. In cases where the residual drifts due to the seismic loads are not considerable, the most probable collapse mode is the local failure of the beams. This is due to the fact that the rate of temperature variation under fire is lower for the protected columns than that for the protected beams (see Figure 8). For instance, the temperature of the protected columns under standard fire reaches $500^{\circ} \mathrm{C}$ during a 4-hour period of the time which corresponds to a negligible reduction in material strength. Hence, the yield or buckling of columns is expected to occur later than the failure of beams.

The variation of deflection versus time for a sample beam in the standard fire scenario is depicted in Figure 9. The mechanical behavior of the beam members belonging to the damaged and undamaged structures is compared in this figure. The structural failure happens when the slope of the curve approaches infinity. It can be observed that the reduction rate of fire resistance time due to the damage of fireproofing material for the beams belonging to the low-, medium-, and high-rise sample frames is approximately $25 \%$, $13 \%$, and $8 \%$, respectively. This is mainly due to the fact that the inter-story drift control provided in seismic design specifications leads to larger sections for higher frames with lower utilization factor, which increases the resistance against fire loads. It is notable that the plastic behavior of the damaged beam in the end regions leads to redistribution of the moments along the length of the beam, mitigating the reduction rate of fire resistance.

When the residual IDR is considerable, the collapse of the frames is likely to happen in the sideway mode. The lateral resistance of the moment- resisting frame structures is mainly provided by the rotational strength of the beam-to-column connections. Therefore, the damage of the fireproofing material at the two ends of the beam significantly reduces the lateral resistance of the structure, leading to the sideway collapse. The behavior of sample frames under post-earthquake fire is investigated by two different methods, as described in the following subsections.

\subsection{Method 1}

To assess the residual drift response limit beyond which the side-way collapse mode is expected to dominate other collapse mechanisms, a trial and error approach is employed. On each try, the "push and pull" analysis with the first mode load pattern is followed by thermal-mechanical analysis to determine the response parameters. The target displacement for the pushover analysis on each try is increased until the structural instability is detected in pushover analysis. The collapse mechanism and the fire resistance time of the sample frames are obtained using this method. The fire resistance Reduction Factor ( $\mathrm{RF}$ ) for each of the case study structures is calculated by dividing the fire resistance time of the damaged frame by that of the undamaged one. For the damaged frames, it is assumed that the fireproofing is delaminated at two ends of the beam members. The variation of RF versus Residual Roof Drift Ratio (RRDR) for the considered cases is presented in Figure 10. The slope of the curves does not vary until the RRDR reaches a threshold limit at which the slope of the curve suddenly ramps down. This point corresponds to the Critical Residual Drift Ratio (CRDR) at which the collapse mechanism changes from local failure of beams to the side-way global collapse. The CRDR of the 5-, 10- and 15-story frames is $4.7 \%$, $1.33 \%$, and $0.9 \%$, respectively. Therefore, it can be concluded that with an increase in height, the CRDR is reduced. This is mainly due to the grated $P-\Delta$ effect of the higher structures.

The side-way collapse mode is represented in terms of drift ratio. The detected collapse mechanism and the drift ratio variation of the highest firesubjected story in an instant after the occurrence of 


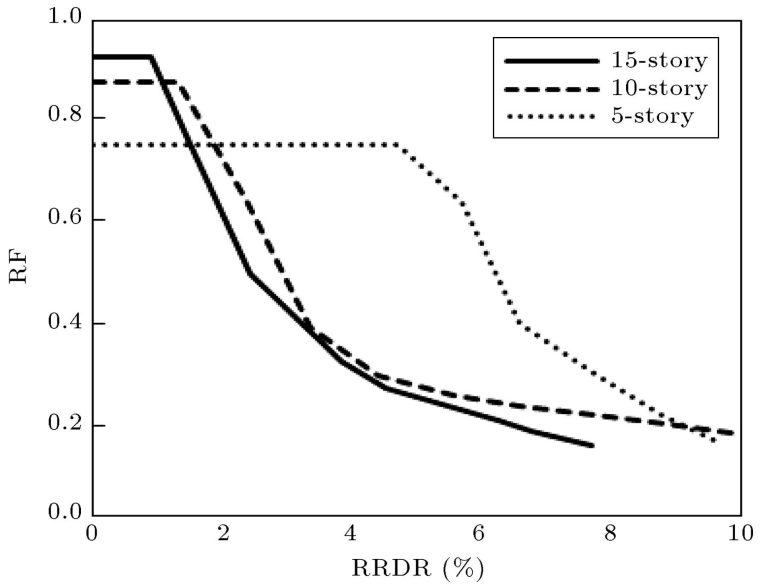

Figure 10. Variation of Reduction Factor (RF) versus residual roof drift ratio.

CRDR are provided in Figure 11. The collapse of the frame happens when the slope of the time-drift ratio curve approaches infinity.

To investigate the effect of fireproofing delamination on the fire resistance rating of the considered frames, the variation of RF versus RRDR is obtained again, supposing that no damage to fireproofing has occurred. The comparison of the $\mathrm{RF}$ variation for the cases with Damaged Fireproofing (DF) and cases with Undamaged Fireproofing (UF) is illustrated in Figure 12.

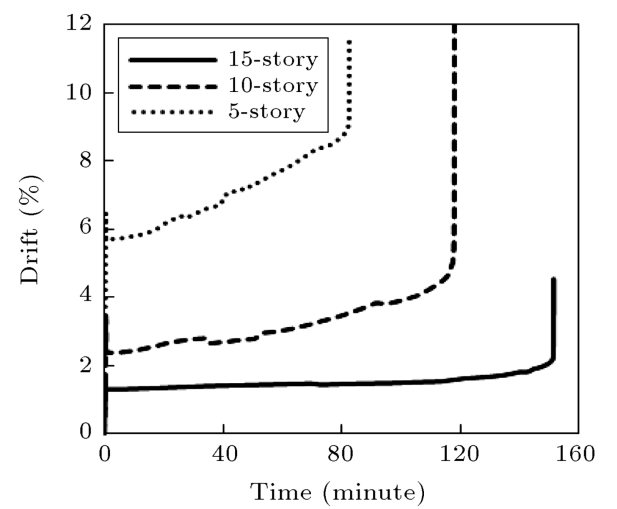

It is found that the average of $\mathrm{RF}$ for the $\mathrm{DF}$ samples varies between $43 \%$ and $58 \%$, depending on the residual drift and structural characteristics. For the UFs, the RF values stand in the range of $60 \%$ to $88 \%$. For residual drifts lower than CRDR, only the delamination of fireproofing reduces the fire resistance rating, while for larger drifts, both the fireproofing delamination and residual drifts considerably reduce the fire resistance time.

Considering that the size of damage to the fireproofing material mainly depends on the inter-story drift response, this factor is precisely taken into account through the implementation of time-history analyses, as described in Method 2.

\subsection{Method 2}

To take the damage of fireproofing into consideration for analyzing the behavior of the structural systems under post-earthquake fire, the actual drift response of the stories must be appropriately determined. Time history analysis is an efficient tool to capture the most precise dynamic response of the structural systems to seismic excitations. In this part of the study, two sets of near- and far-fault ground motion records are selected for time history analysis. Each of the ground motion record sets is scaled to the MCE hazard level before being applied to structures. Post-earthquake analysis of each of the records is a two-step procedure, where
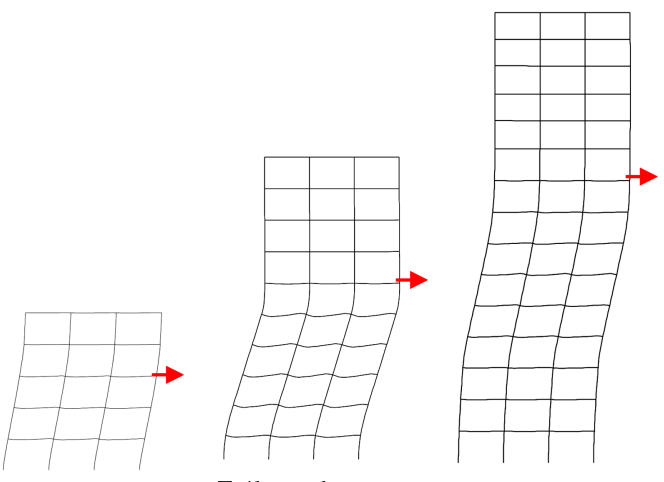

Failure shapes

Figure 11. Drift ratio versus time for the highest fire-subjected story.
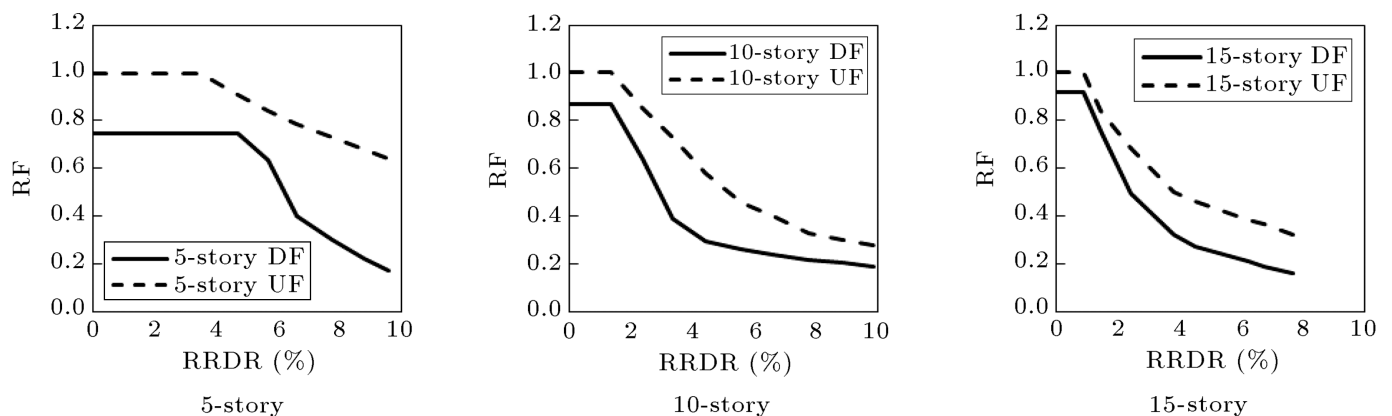

Figure 12. Variation of Reduction Factor (RF) versus Residual Roof Drift Ratio (RRDR) for Damaged Fireproofing (DF) and Undamaged Fireproofing (UF) samples. 

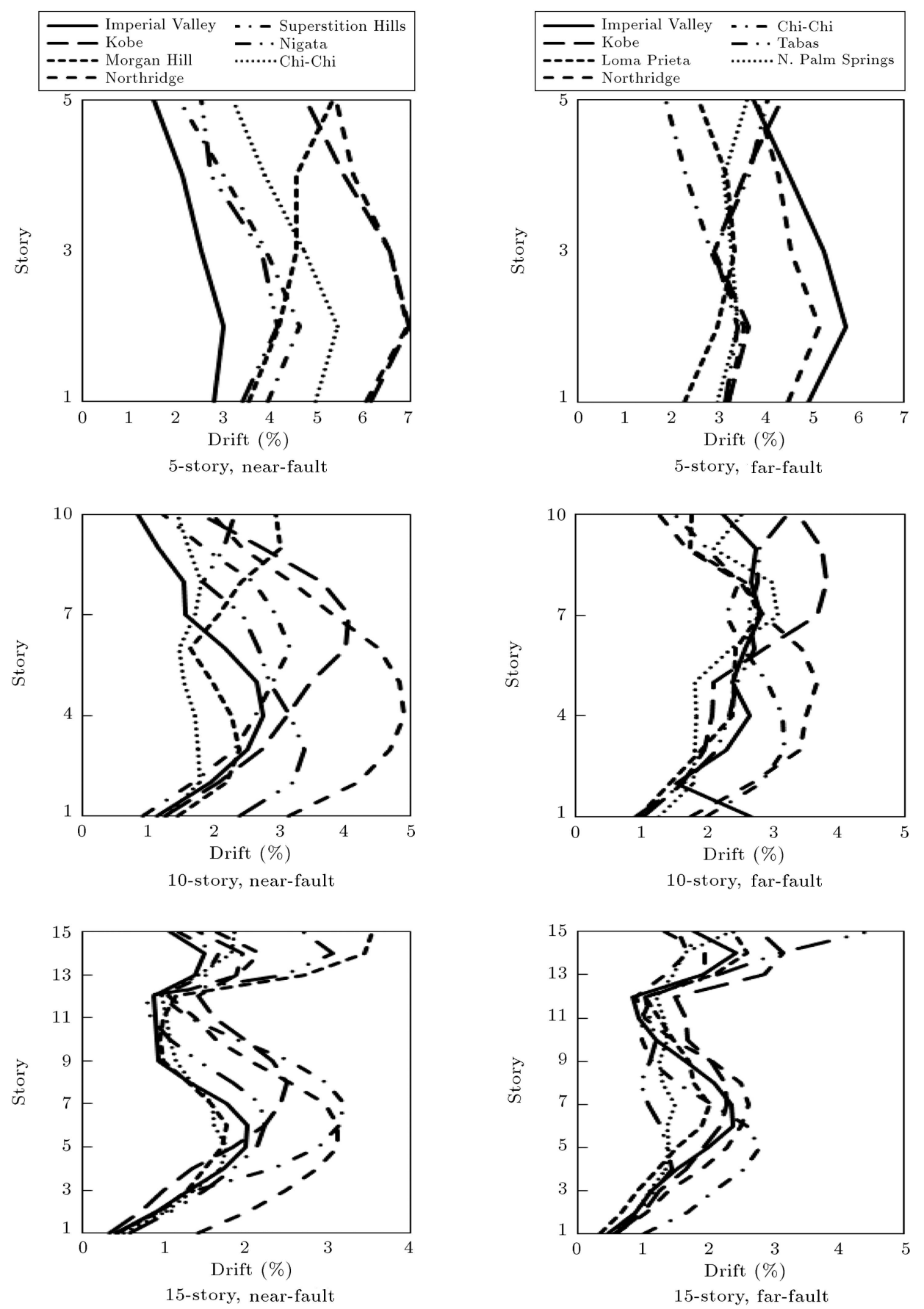

Figure 13. Maximum inter-story drift ratio response.

the time-history analysis is followed by a thermalmechanical analysis. In the thermal-mechanical analysis phase, it is assumed that the fireproofing of the beams is removed within the stories for which the drift ratio demand exceeds the $2.5 \%$ limit. The maximum drift ratio for each of the sample structures is shown in Figure 13. It is observed that the maximum drift response of the frames is averagely $20 \%$ greater than far fault motions in case of near-fault excitations.

Three frequently used performance levels in seismic assessment studies include Immediate Occupancy
(IO), Life Safety (LS), and Collapse Prevention (CP). ASCE 41 standard defines the performance level of steel moment-resisting frames based on the Maximum Inter-story Drift Ratio (MIDR), where the MIDR less than $0.7 \%$ coincides with the IO limit state, the MIDR lower than $2.5 \%$ and larger than $0.7 \%$ corresponds to the LS performance level, and MIDR greater than $2.5 \%$ and the MIDR lower than $5.0 \%$ coincides with the CP limit state [35]. Considering that the IDR demand greater than $2.5 \%$ may cause the removal of the fireproofing, it can be deduced that if the 
performance of the structure exceeds the LS limit state, the fireproofing is delaminated in some parts of the structures.

To evaluate RF under each of the ground motion excitations, the thermal-mechanical analysis follows the time-history analysis. The damage status of fireproofing in each of the stories during the thermalmechanical analysis is determined based on the IDR demand obtained from time history analysis. The results of the analyses are represented in terms of the fire endurance time and detected collapse mechanism.

The RF values and the stories on which the fireproofing is delaminated for each of the sample structures are provided in Table 5. The star signs indicate the stories on which the fireproofing is damaged in the end regions of the beams due to seismic loads. The results of the study imply that the size of damage to the fireproofing is less than that for higher frames.

The average RF for the FF and NF ground motions is provided in Figure 14. The RF for the NF records is slightly greater than that for $\mathrm{FF}$ records. The average RF for 5-, 10-, and 15-story frames is $74 \%$, $87 \%$, and $96 \%$, respectively.

The variation of $R F$ versus RRDR is presented in Figure 15. In each plot, the solid curves are obtained using Method 1 and the point markers demonstrate the results of Method 2. The points lying on the UF curve indicate the cases in which the damage to fireproofing is not detected so that the collapse of the structure under the standard fire occurs by local failure of the beams. The points coinciding with the zero-

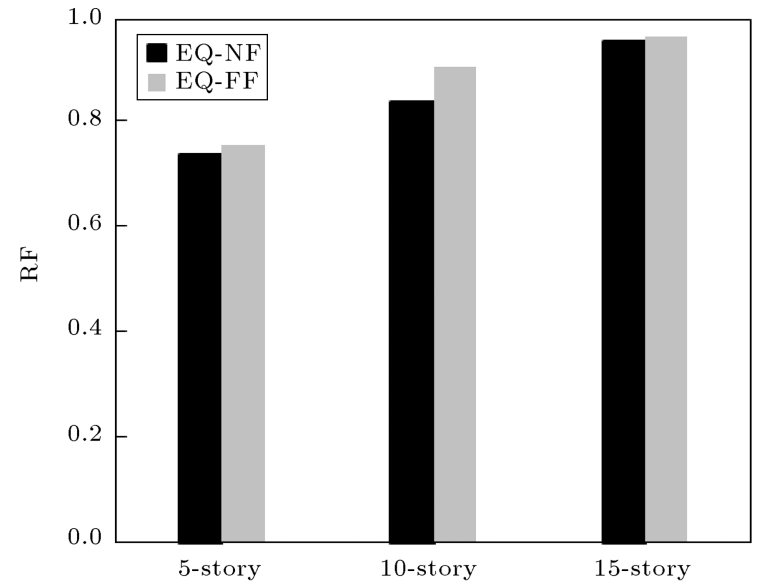

Figure 14. Average Reduction Factors (RFs) for the sample frames.

slope part of the DF curve represent the cases where fireproofing is damaged on some or all of the firesubjected stories and the failure of the beam dominates other collapse mechanisms. For the other cases, the collapse mechanism is in the form of side-way collapse, where the residual drifts are considerable and the fireproofing is damaged either in some or all parts of the structure. It can be observed that the difference in RF values derived from Methods 1 and 2 is less than $5 \%$.

The average RRDR for the taller stories is lower than that for shorter frames. This is mostly due to the fact that taller frames are designed for most strict requirements to control lateral displacements as well

Table 5. Reduction Factor (RF) and damaged stories.

\begin{tabular}{|c|c|c|c|c|c|c|c|c|c|c|c|c|c|c|c|c|c|c|c|c|c|}
\hline \multirow{3}{*}{ Ground motions } & \multicolumn{4}{|c|}{ 5-story frame } & \multicolumn{7}{|c|}{ 10-story frame } & \multicolumn{10}{|c|}{ 15-story frame } \\
\hline & \multicolumn{3}{|c|}{ Fire stories } & \multirow[b]{2}{*}{$\mathbf{R F}$} & \multicolumn{6}{|c|}{ Fire stories } & \multirow[b]{2}{*}{$\mathbf{R F}$} & \multicolumn{9}{|c|}{ Fire stories } & \multirow[b]{2}{*}{$\mathbf{R F}$} \\
\hline & 1 & 2 & 3 & & 1 & 2 & 3 & 4 & 5 & 6 & & 1 & 2 & 3 & 4 & 5 & 6 & 7 & 8 & 9 & \\
\hline Imperial Valley-NF & $*$ & $*$ & $*$ & 0.75 & & & $*$ & $*$ & $*$ & & 0.87 & & & & & & & & & & 1.00 \\
\hline Kobe-NF & $*$ & $*$ & $*$ & 0.70 & & & $*$ & $*$ & $*$ & * & 0.74 & & & & & & & & $*$ & & 0.92 \\
\hline Morgan Hill-NF & $*$ & $*$ & $*$ & 0.75 & & & & & & & 1.00 & & & & & & & & & & 1.00 \\
\hline Northridge-NF & $*$ & $*$ & $*$ & 0.67 & $*$ & $*$ & $*$ & $*$ & $*$ & $*$ & 0.49 & & & & $*$ & $*$ & $*$ & $*$ & $*$ & & 0.85 \\
\hline Superstition Hills-NF & $*$ & $*$ & $*$ & 0.75 & & & & $*$ & $*$ & $*$ & 0.87 & & & & & $*$ & $*$ & $*$ & $*$ & $*$ & 0.92 \\
\hline Nigata-NF & $*$ & $*$ & $*$ & 0.75 & & $*$ & $*$ & $*$ & $*$ & $*$ & 0.87 & & & & & & & & & & 1.00 \\
\hline Chi-Chi-NF & $*$ & $*$ & $*$ & 0.75 & & & & & & & 1.00 & & & & & & & & & & 1.00 \\
\hline Imperial Valley-FF & $*$ & $*$ & $*$ & 0.75 & $*$ & & & $*$ & & $*$ & 0.87 & & & & & & & & & & 1.00 \\
\hline Kobe-FF & $*$ & $*$ & $*$ & 0.75 & & & & & & $*$ & 0.87 & & & & & & & & & & 1.00 \\
\hline Loma Prieta-FF & & $*$ & $*$ & 0.75 & & & & & & & 1.00 & & & & & & & & & & 1.00 \\
\hline Northridge-FF & $*$ & $*$ & $*$ & 0.75 & & $*$ & $*$ & $*$ & $*$ & $*$ & 0.87 & & & & & & $*$ & $*$ & $*$ & & 0.92 \\
\hline Chi-Chi-FF & $*$ & $*$ & $*$ & 0.75 & & $*$ & $*$ & $*$ & $*$ & $*$ & 0.87 & & & & $*$ & $*$ & $*$ & & & & 0.92 \\
\hline Tabas-FF & $*$ & $*$ & $*$ & 0.75 & & & & & & $*$ & 0.87 & & & & & & & & & & 1.00 \\
\hline N. Palm Springs-FF & $*$ & $*$ & $*$ & 0.75 & & & & & & & 1.00 & & & & & & & & & & 1.00 \\
\hline
\end{tabular}



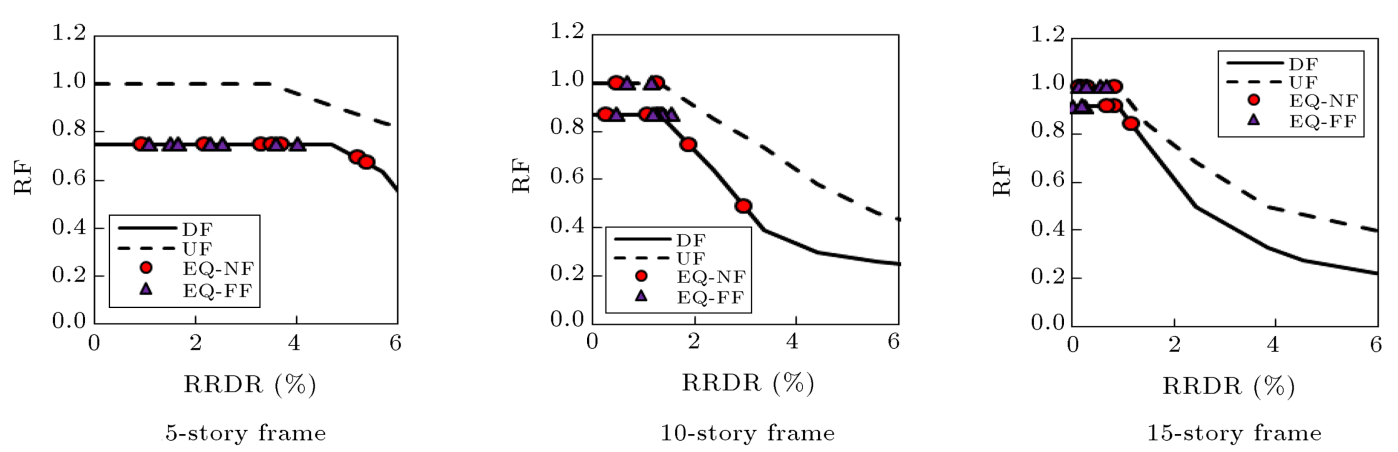

Figure 15. Reduction Factor (RF) values versus residual roof drift ratios.

as the greater redundancy for the frames with more stories.

\section{Conclusions}

The effect of seismic damage on the fire resistance of the protected steel moment-resisting frames was investigated in this paper. For this purpose, the post-earthquake analysis of the three sample steel moment frame structures with 5, 10, and 15 stories was performed. Two different methods were employed to determine the response of the frames to the postearthquake fire. In Method 1, the pushover analysis with different target displacements was employed to simulate the response of the sample frames to the seismic loads with different intensities. Then, the thermalmechanical analysis followed the pushover analysis to determine the response of the structures to the postearthquake fire loads. In this method, it was assumed that the fireproofing was delaminated in the end regions of the beam members. In Method 2, the seismic response of the structures was determined using time history analysis. In this method, it was assumed that the fireproofing of the members was delaminated when the Inter-story Drift Ratio (IDR) demand of the story exceeded $2.5 \%$ limit. Time history analysis was conducted using two suites of near and far fault ground motions. The ground motion records were scaled to the Maximum Considered Earthquake (MCE) hazard level. The numerical modeling and analysis of the frames were implemented using ABAQUS finite element software. The main findings of the research are summarized as follows:

1. The collapse mode of the steel moment frame structures under post-earthquake fire depends on the residual inter-story drift ratio. For the considered sample frames, when the residual IDR exceeds $4.7 \%, 1.33 \%$, and $0.9 \%$ for the 5 -, 10 -, and 15 -story frames, respectively, the collapse of the structure occurs in the sideway mode;

2. The reduction of fire resistance time due to the effects of MCE scaled near-fault ground motions ranges from $5 \%$ to $27 \%$ for the considered sample frames. The amount of fire resistance reduction extends from $4 \%$ to $26 \%$ for far fault motions;

3. The effect of fireproofing delamination on the fire resistance of the steel frame structure is considerable. Therefore, the delamination of fireproofing must be incorporated in the modeling of steel structures under fire;

4. The comparison of results obtained using two considered methods demonstrates that the application of pushover analysis is a suitable approach to determining the behavior of the structures under post-earthquake fire;

5. The assumption that fireproofing is completely removed in the end regions of the beam members does not introduce considerable approximation in estimation of fire endurance time under MCE seismic excitations;

6. With an increase in the height, the IDR demand of the structures decreases, resulting in less damage to the fireproofing.

\section{References}

1. Cousins, W., Thomas, G.C., Heron, D.W., et al. "modelling the spread of post-earthquake fire in Wellington City", In Proc. of the 2002 Technical Conference and $A G M$, New Zealand Society for Earthquake Engineering, Napier (2002).

2. Buchanan, A.H., Fire Engineering Design Guide, Centre for Advanced Engineering, University of Canterbury (2001).

3. Chicchi, R. and Varma, A.H. "Research review: Postearthquake fire assessment of steel buildings in the United States", Advances in Structural Engineering, 21(1), pp. $138-154$ (2018). DOI: 1369433217711617

4. Nishino, T., Tanaka, T., and Hokugo, A. "An evaluation method for the urban post-earthquake fire risk considering multiple scenarios of fire spread and evacuation", Fire Safety Journal, 54, pp. 167-180 (2012). 
5. Della Corte, G., Landolfo, R., and Mazzolani, F. "Post-earthquake fire resistance of moment resisting steel frames", Fire Safety Journal, 38(7), pp. 593-612 (2003).

6. Faggiano, B. "Fire after earthquake", In Proc. from WG1 Meeting on Urban Habitat Constructions under Catastrophic Event, Prague (2007).

7. Faggiano, B., De Gregorio, D., and Mazzolani, F. "Assessment of the robustness of structures subjected to fire following earthquake through a performance-based approach", In Proc. Int. Conference Urban Habitat Constructions under Catastrophic Events (COST C26 Action), Naples, Italy (2010).

8. Zaharia, R. and Pintea, D. "Fire after earthquake analysis of steel moment resisting frames", International Journal of Steel Structures, 9(4), pp. 275-284 (2009).

9. Behnam, B. and Ronagh, H.R. "Behavior of momentresisting tall steel structures exposed to a vertically traveling post-earthquake fire", The Structural Design of Tall and Special Buildings, 23(14), pp. 1083-1096 (2014).

10. Behnam, B. and Ronagh, H.R. "Post-earthquake fire performance-based behavior of unprotected moment resisting 2D steel frames", KSCE Journal of Civil Engineering, 19(1), pp. 274-284 (2015).

11. Memari, M., Mahmoud, H., and Ellingwood, B. "Post-earthquake fire performance of moment resisting frames with reduced beam section connections", Journal of Constructional Steel Research, 103, pp. 215-229 (2014).

12. Elhami Khorasani, N., Garlock, M., and Gardoni, P. "Probabilistic performance-based evaluation of a tall steel moment resisting frame under post-earthquake fires", Journal of Structural Fire Engineering, 7(3), pp. 193-216 (2016).

13. Behnam, B. "Structural response of vertically irregular tall moment-resisting steel frames under pre-and postearthquake fire", The Structural Design of Tall and Special Buildings, 25(12), pp. 543-557 (2016).

14. Braxtan, N.L. and Pessiki, S., Seismic Performance of Sprayed Fire Resistive Material (SFRM) on Steel Moment Frame Buildings, Lehigh University (2010).

15. Leo Braxtan, N. and Pessiki, S. "Bond performance of SFRM on steel plates subjected to tensile yielding", Journal of Fire Protection Engineering, 21(1), pp. 3755 (2011).

16. Keller, W.J. and Pessiki, S. "Effect of earthquakeinduced damage on the side-way response of steel moment-frame buildings during fire exposure", Earthquake Spectra, 31(1), pp. 273-292 (2015).

17. Quiel, S.E. and Garlock, M.E. "Modeling high-rise steel framed buildings under fire", In Structures Cong. Crossing Borders (2008).
18. Iranian National Building Regulations Loads on Building code NO. 6, Iran National Building Regulations Center, INBR publications, Tehran (2008).

19. Standard No. 2800, Building \& Housing Research Center, Iranian Code of Practice for Seismic Resistant Design of Buildings, Iran (2015).

20. ANSI/AISC 360-10, American Institute of Steel Construction, INC, Specification for Structural Steel Buildings, Chicago, Illinois (2010).

21. Daryan, A.S., Sadri, M., Saberi, H., et al. "Rotational castellated steel beams", The Structural Design of Tall and Special Buildings, 22(12), pp. 941-953 (2013).

22. Toh, W., Tan, K., and Fung, T. "Strength and stability of steel frames in fire: Rankine approach", Journal of Structural Engineering, 127(4), pp. 461-469 (2001).

23. Charney, F.A. and Marshall, J. "A comparison of the Krawinkler and scissors models for including beamcolumn joint deformations in the analysis of momentresisting steel frames", Engineering Journal-American Institute of Steel Construction INC, 43(1), pp. 31-48 (2006).

24. EN 1993-1-2 European standard, Eurocode 3: Design of steel structures, Part 1-2: Structural fire design, CEN, Brussels, Belgium (2005).

25. Bastami, M., Chaboki-Khiabani, A., Baghbadrani, M., et al. "Performance of high strength concretes at elevated temperatures", Scientia Iranica, 18(5), pp. 1028-1036 (2011).

26. Rubert, A. and Schaumann, P. "Structural steel and plane frame assemblies under fire action", Fire Safety Journal, 10(3), pp. 173-184 (1986).

27. Lien, K., Chiou, Y.J., Wang, R.Z., et al. "Vector form intrinsic finite element analysis of nonlinear behavior of steel structures exposed to fire", Engineering Structures, 32(1), pp. 80-92 (2010).

28. Sun, R., Huang, Z., and Burgess, I.W. "Progressive collapse analysis of steel structures under fire conditions", Engineering Structures, 34, pp. 400-413 (2012).

29. Memari, M. and Mahmoud, H. "Performance of steel moment resisting frames with RBS connections under fire loading", Engineering Structures, 75, pp. 126-138 (2014).

30. Baker, J.W. "Quantitative classification of near-fault ground motions using wavelet analysis", Bulletin of the Seismological Society of America, 97(5), pp. 1486-1501 (2007).

31. FEMA P695 Federal Emergency Management Agency, Qualification of Building Seismic Performance Factors, USA (2009).

32. EN 1991-1-2 European standard, Eurocode 1: Action on structures, Part 1-2: Action on Structures Exposed to Fire, CEN, Brussels, Belgium (2002).

33. Underwriters' Laboratories, Fire Resistance Directory, 1 (1992). 
34. Cadorin, J.F., Pintea, D., Dotreppe, J.C., et al. "A tool to design steel elements submitted to compartment fires-OZone V2. Part 2: Methodology and application", Fire Safety Journal, 38(5), pp. 429-451 (2003).

35. ASCE Publications, Seismic Rehabilitation of Existing Buildings, 41 (2007).

\section{Biographies}

Pouria Mirzaei is a PhD student in Earthquake Engineering at Semnan University of Iran. He has received his MSc degree from Iran University of Science and Technology (IUST) in 2012. He is working in a Civil Engineering Company as a consultant engineer. His major specialty relates to fire engineering and modeling of structural systems.

Mohsen Gerami is a Professor of Civil Engineering at Semnan University of Iran. He has received his PhD from Tarbiat Modares University in 2003. His studies cover a wide range of topics in the structural and earthquakes engineering, including dynamic analysis of structures, performance-based engineering, near-fault ground motion effects, and fire engineering. 